\author{
Т. Ю. САЛИНА, Т. И. МОРОЗОВА
}

ФГБОУ ВО «Саратовский ГМУ им. В. И. Разумовского» МЗ РФ, г. Саратов, РФ

Цель: изучить распространенность и спектр мутаций в генах $k a t G$, inh $A, \operatorname{ahp} C$, кодирующих лекарственную устойчивость (ЛУ) к изониазиду, и в гене $r p o B$, кодирующем ЛУ к рифампицину, у больных туберкулезом легких разного возраста.

Материалы и методы. Обследовано 253 пациента, которые в зависимости от возраста разделены на 3 группы (группа 1 - от 18 до 30 лет, группа 2 - от 31 года до 60 лет, группа 3 - от 61 года до 80 лет). Исследования проводили на биологических микрочипах с применением набора реагентов «ТВ-Биочип» (Россия).

Результаты. В группах 1 и 2 по сравнению с группой 3 достоверно чаще регистрировали мутации одновременно в генах $k a t G$, inhA, $a h p C$ и в гене $r p o B$, то есть чаще наблюдалась множественная лекарственная устойчивость (МЛУ) (32,4 и 36,1\% против 13,2\% соответственно). Мутации в гене $k a t G$ в целом (включая МЛУ + изолированную устойчивость к изониазиду) также достоверно чаще встречались в группах 1 и $2(30,9$ и $32,7 \%)$ по сравнению с группой $3(10,5 \%)$. Аналогичные изменения выявлены и в отношении распространенности неблагоприятного вида мутации ser 315-> Thr гена $k a t G$, которая зарегистрирована в 23,5\% случаев в группе 1, в 21,8\% случаев - в группе 2 и в $7,9 \%$ - в группе 3 . В группе 3 реже регистрировали мутации в гене $r р о B$ (включая МЛУ) - 26,5\% против 45,5\% в группе 1 и 46,9\% в группе 2. Достоверных различий в спектре мутаций в гене $r p o B$ между обследуемыми группами пациентов не получено. Таким образом, установлен достоверно более низкий уровень ЛУ к изониазиду и рифампицину у больных туберкулезом пожилого и старческого возраста по сравнению с пациентами молодого и среднего возраста, регистрируемый на уровне генетических мутаций.

Ключевые слова: туберкулез, мутации в генах, резистентность, изониазид, рифампицин

Для цитирования: Салина Т. Ю., Морозова Т. И. Распространенность мутаций в генах микобактерий туберкулеза, кодирующих лекарственную устойчивость к изониазиду и рифампицину, у больных туберкулезом в разных возрастных группах // Туберкулёз и болезни лёгких. - 2019. - Т. 97, № 4. - С. 12-18. http://doi.org/10.21292/2075-1230-2019-97-4-12-18

\title{
PREVALENCE OF MUTATIONS IN MYCOBACTERIUM TUBERCULOSIS GENES CODING RESISTANCE TO ISONIAZID AND RIFAMPICIN IN TUBERCULOSIS PATIENTS FROM DIFFERENT AGE GROUPS
}

\section{T. YU. SALINA, T. I. MOROZOVA}

\section{Saratov State Medical University named after V. I. Razumovsky, Saratov, Russia}

The objective: to study the prevalence and ranges of mutations in $k a t G$, inh $A$, and $a h p C$ genes coding resistance to isoniazid, and in $r p o B$ gene coding resistance to rifampicin in patients with pulmonary tuberculosis from different age groups.

Subjects and methods. 253 patients were examined; based on their age they were divided into 3 groups (Group 1 - from 18 to 30 years, Group 2 from 31 to 60 years, group 3 - from 61 to 80 years). Biological microchips with TB-Biochip reagent kit (Russia) were used.

Results. In Groups 1 and 2, compared to Group 3, mutations were recorded more often simultaneously in katG, inhA, ahpC genes and $r p o B$ genes which meant that multiple drug resistance (MDR) prevailed (32.4 and $36.1 \%$ against $13.2 \%$, respectively). In general, mutations in $k a t G$ gene (including MDR + isolated isoniazid resistance) were also confidently more frequent in Groups 1 and 2 (30.9 and 32.7\%) versus Group 3 (10.5\%). Similar changes were found in the prevalence of the adverse type of ser 315-> Thr mutation of $k a t G$ gene, which was registered in $23.5 \%$ of cases in Group 1, in 21.8\% of cases in Group 2, and in 7.9\% - in Group 3. In Group 3, mutations in $r p o B$ gene (including MDR) were less frequently recorded and made $26.5 \%$ versus $45.5 \%$ in Group 1 and $46.9 \%$ in Group 2. There were no confident differences in ranges of mutations in $r p o B$ gene between the examined groups of patients. Thus, a significantly lower level of resistance to isoniazid and rifampicin in elderly and senile tuberculosis patients was found compared to young and middle-aged patients, which was registered at the level of genetic mutations.

Key words: tuberculosis, gene mutations, resistance, isoniazid, rifampicin

For citations: Salina T.Yu., Morozova T.I. Prevalence of mutations in Mycobacterium tuberculosis genes coding resistance to isoniazid and rifampicin in tuberculosis patients from different age groups. Tuberculosis and Lung Diseases, 2019, Vol. 97, no. 4, P. 12-18. (In Russ.) http://doi. org/10.21292/2075-1230-2019-97-4-12-18

Важнейшей проблемой современной фтизиатрии, вышедшей в настоящее время на одно из первых мест, является значительное распространение микобактерий туберкулеза (МБТ) с множественной и широкой лекарственной устойчивостью (МЛУ и ШЛУ) [7, 6]. Россия входит в число стран с наибольшим бременем туберкулеза с МЛУ
(МЛУ-туберкулеза) [1, 2, 6]. МЛУ-туберкулез представляет большую эпидемическую опасность, значительно снижает эффективность лечения и приводит к большим экономическим затратам [7].

Для эффективной борьбы с распространением МЛУ-туберкулеза необходимо дальнейшее изучение факторов, влияющих на формирование лекар- 
ственной устойчивости (ЛУ). Многочисленными молекулярно-генетическими исследованиями [3, 7 , $8,10,13,14]$ доказано, что в основе формирования ЛУ МБТ лежит развитие хромосомных мутаций в генах, возникающих в основном в результате неадекватного и прерванного лечения. Однако анализ большого числа научных публикаций показывает, что только этих факторов недостаточно для объяснения эволюции ЛУ туберкулеза, так как лекарственно-устойчивые штаммы МБТ развиваются и в странах с хорошо финансируемыми системами здравоохранения и налаженным строго контролируемым лечением [7]. Предполагаем, что возраст может являться фактором, влияющим на формирование ЛУ МБТ в силу особенностей физиологических процессов у лиц разных возрастных категорий.

Цель исследования: изучить распространенность и спектр мутаций в генах $k a t G, i n h A, \operatorname{ahp} C$ и в гене $r p o B$, кодирующих ЛУ к изониазиду (INH) и рифампицину (RIF) в штаммах МБТ, выделенных от больных туберкулезом разного возраста.

\section{Материалы и методы}

Проведен молекулярно-генетический анализ клинических изолятов МБТ, полученных из мокроты 253 больных туберкулезом легких (впервые выявленные - 241 (95,3\%), рецидивы - 12 (4,8\%) человек), находившихся на стационарном лечении в Саратовском областном клиническом противотуберкулезном диспансере с 2006 по 2015 г., из них мужчин было 167 (66\%), женщин - 86 (34\%). Возраст обследованных - от 18 до 80 лет. В зависимости от возраста пациенты распределены на 3 группы. Группу 1 составили 68 молодых больных в возрасте от 18 до 30 лет, группу 2 - 147 пациентов в возрасте от 31 года до 60 лет; группу 3 - 38 больных пожилого и старческого возраста (от 61 года до 80 лет). Среди клинических форм туберкулеза у обследованных пациентов преобладал инфильтративный туберкулез легких - 191 (75,5\%). Другие формы туберку- леза (диссеминированная, очаговая, туберкулема, кавернозная и фиброзно-кавернозная) встречались гораздо реже. Распределение больных по клиническим формам в анализируемых группах было сопоставимо и достоверно не различалось (табл. 1).

У всех пациентов выделение ДНК микобактерий туберкулезного комплекса и определение спектра генетических мутаций МБТ, кодирующих ЛУ к INH и RIF, проводили в образцах мокроты до начала антибактериальной терапии. Использовали метод биологических микрочипов с применением набора реагентов «ТВ-БИОЧИП» (ООО «Биочип-ИМБ», г. Москва). Результаты реакции регистрировали на портативном анализаторе биочипов «Чипдетектор-01» с соответствующим программным обеспечением Imageware (Россия). В случае обнаружения мутаций в генах $k a t G, \operatorname{inh} A, \operatorname{ahpC}$ штаммы МБТ относили к устойчивым к INH, при наличии мутаций в гене $r p o B$ - к устойчивым к RIF, при наличии одновременно мутаций в одном или нескольких генах $k a t G, \operatorname{inh} A, \operatorname{ahp} C$ в сочетании с мутациями в гене $r p o B-$ к множественно-лекарственно-устойчивым.

Статистическую обработку результатов исследования проводили с использованием компьютерных программ Microsoft ${ }^{\circledR}$ Excel для Windows $\mathrm{XP}^{\circledR}$ и Statistica 6.0. Для сравнения достоверности различий в двух группах использовали $\chi^{2}$-тест. В качестве критического уровня достоверности принят критерий 0,05.

\section{Результаты исследования}

Анализ распространенности мутаций в генах $k a t G, i n h A, a h p C$ и rрoB, кодирующих ЛУ к INH и RIF, у больных туберкулезом разных возрастных групп представлен в табл. 2. МЛУ наиболее часто встречалась среди пациентов групп 1 и 2 и составила $22 / 68(32,4 \%)$ и 53/147 $(36,1 \%)$ соответственно, что было достоверно больше по сравнению с группой $3-5 / 38(13,2 \%), p_{1-3}=0,0262$ и $p_{2-3}=0,0070$. Достоверных различий в отношении распростра-

Таблища 1. Распределение больных в группах по клиническим формам в зависимости от возраста Table 1. Distribution of patients as per clinical forms and age

\begin{tabular}{|c|c|c|c|c|c|c|c|}
\hline \multirow{2}{*}{ Клиническая форма туберкулеза } & \multicolumn{2}{|c|}{ Группа $1(n=68)$} & \multicolumn{2}{|c|}{ Группа $2(n=147)$} & \multicolumn{2}{|c|}{ Группа $3(n=38)$} & \multirow{2}{*}{$p$} \\
\hline & абс. & $\%$ & абс. & $\%$ & абс. & $\%$ & \\
\hline Инфильтративная & 47 & 69,1 & 118 & 80,3 & 29 & 76,3 & $\begin{array}{l}1-2=0,0782 \\
2-3=0,5889\end{array}$ \\
\hline Очаговая & 3 & 4,4 & 1 & 0,68 & 1 & 2,6 & $\begin{array}{l}1-2=0,5771 \\
2-3=0,7791\end{array}$ \\
\hline Диссеминированная & 9 & 13,2 & 12 & 8,2 & 3 & 7,9 & $\begin{array}{c}1-2=0,2480 \\
2-3-\end{array}$ \\
\hline Туберкулема & 1 & 1,5 & 7 & 4,8 & 4 & 10,5 & $\begin{array}{l}1-2=0,3345 \\
2-3=0,1743\end{array}$ \\
\hline Генерализованная & 1 & 1,5 & 2 & 1,4 & 0 & 0 & - \\
\hline $\begin{array}{l}\text { Кавернозная } \\
\text { и фиброзно-кавернозная }\end{array}$ & 7 & 10,3 & 7 & 4,8 & 1 & 2,6 & $\begin{array}{l}1-2=0,1706 \\
2-3=0,6001\end{array}$ \\
\hline
\end{tabular}


Таблища 2. Распространенность мутаций в генах $k a t$ G, inhA, ahp C и rpoB, кодирующих лекарственную устойчивость к изониазиду и рифампицину, у больных туберкулезом разных возрастных групI

Table 2. Prevalence of mutations in kat G, inhA, ahp C, and rpoB genes coding resistance to isoniazid and rifampicin in tuberculosis patients from different age groups

\begin{tabular}{|c|c|c|c|c|c|c|c|}
\hline \multirow{2}{*}{ Мутации в генах } & \multicolumn{2}{|c|}{ Группа $1(n=68)$} & \multicolumn{2}{|c|}{ Группа $2(n=147)$} & \multicolumn{2}{|c|}{ Группа 3 ( $n=38)$} & \multirow{2}{*}{$p$} \\
\hline & абс. & $\%$ & абс. & $\%$ & абс. & $\%$ & \\
\hline $\begin{array}{l}\text { МЛУ (мутации одновременно в генах katG, inhA, } \\
\text { ahpC и rpoB) }\end{array}$ & 22 & 32,4 & 53 & 36,1 & 5 & 13,2 & $\begin{array}{l}1-2=0,6686 \\
1-3=0,0262 \\
2-3=0,0070\end{array}$ \\
\hline $\begin{array}{l}\text { Изолированная устойчивость к изониазиду } \\
\text { (мутации только в генах katG, inhA, ahpC) }\end{array}$ & 16 & 23,5 & 23 & 15,6 & 6 & 15,8 & $\begin{array}{l}1-2=0,1618 \\
1-3=0,1618 \\
2-3=1,0000\end{array}$ \\
\hline $\begin{array}{l}\text { Изолированная устойчивость к рифампицину } \\
\text { (мутации только в гене гроB) }\end{array}$ & 9 & 13,2 & 16 & 10,9 & 5 & 13,2 & $\begin{array}{l}1-2=0,6710 \\
2-3=0,7300 \\
1-3=1,0000\end{array}$ \\
\hline
\end{tabular}

нения изолированной устойчивости к INH во всех трех группах не получено. Мономутации в генах $k a t G, i n h A, a h p C$ чаще регистрировались в группе 1 $16 / 68$ (23,5\%) против $6 / 38(15,8 \%)$ в группе 3 , но различия не достоверны. Также не выявлено различий по распространению мутаций изолированно в гене $r р о B$ во всех трех группах. Частота встречаемости изолированных мутаций в гене $r p o B$ в группе 1 составила 9/68 (13,2\%), в группе 2 - 16/147 (10,9\%) и группе $3-5 / 38$ (13,2\%).

Спектр наиболее часто встречающихся мутаций в генах $k a t G, i n h A, a h p C$, кодирующих ЛУ к INH, у пациентов разных возрастных групп представлен в табл. 3. Мутации в генах, кодирующие ЛУ к INH в целом, включая МЛУ, обнаружены в 38/68 (56\%) клинических изолятах, полученных от пациентов

Tаблища 3. Спектр наиболее часто встречающихся мутаций в генах $k a t G$, inhA, ahpC, кодирующих лекарственную устойчивость к изониазиду, включая МЛУ, у пациентов разных возрастных групI

Table 3. Ranges of the most frequent mutation in $k a t G$, inhA, and $a h p C$ genes coding resistance to isoniazid, including MDR in the patients from different age groups

\begin{tabular}{|c|c|c|c|c|c|c|c|}
\hline \multirow{2}{*}{$\begin{array}{l}\text { Мутации в генах, кодирующих лУ } \\
\text { к изониазиду (INH) }\end{array}$} & \multicolumn{2}{|c|}{ Группа $1(n=68)$} & \multicolumn{2}{|c|}{ Группа $2(n=147)$} & \multicolumn{2}{|c|}{ Группа $3(n=38)$} & \multirow{2}{*}{$p$} \\
\hline & абс. & $\%$ & абс. & $\%$ & абс. & $\%$ & \\
\hline 1. katG & 21 & 30,9 & 48 & 32,7 & 4 & 10,5 & $\begin{array}{l}1-2=0,7710 \\
1-3=0,0224 \\
2-3=0,0081\end{array}$ \\
\hline 1.1 ser $315->$ Thr 1 & 16 & 23,5 & 32 & 21,8 & 3 & 7,9 & $\begin{array}{l}1-2=0,7448 \\
1-3=0,0434 \\
2-3=0,0520\end{array}$ \\
\hline 1.2 ser $315->\operatorname{Arg}$ & 4 & 5,9 & 6 & 4,1 & 1 & 2,6 & $\begin{array}{l}1-2=0,5458 \\
1-3=0,4952 \\
2-3=0,7740\end{array}$ \\
\hline 1.3 ser $315->$ Gly & 1 & 1,5 & 6 & 4,1 & 0 & 0 & $1-2=0,4505$ \\
\hline $1.4 \operatorname{ser} 315$->Asn & 0 & 0 & 1 & 0,68 & 0 & 0 & - \\
\hline $1.5 \operatorname{ser} 315->$ Gly+ ser 315 ->Asn & 0 & 0 & 3 & 2,1 & 0 & 0 & - \\
\hline 2. inhA & 5 & 7,4 & 9 & 6,1 & 4 & 10,5 & $\begin{array}{l}1-2=0,5843 \\
1-3=0,8432 \\
2-3=0,3118\end{array}$ \\
\hline $2.1 \mathrm{inhA-G16}$ & 1 & 1,5 & 2 & 1,4 & 0 & 0 & - \\
\hline $2.2 \mathrm{inh} A-\mathrm{G} 8$ & 1 & 1,5 & 1 & 0,68 & 0 & 0 & $1-2=0,5503$ \\
\hline 2.3. inhA-A8 & 1 & 1,5 & 1 & 0,68 & 1 & 2,6 & $\begin{array}{l}1-2=0,5553 \\
1-3=0,7456 \\
2-3=0,3811\end{array}$ \\
\hline 2.4. inhA-T15 & 2 & 3,0 & 5 & 3,4 & 2 & 5,3 & $\begin{array}{l}1-2=0,7177 \\
1-3=0,6028 \\
2-3=0,5852\end{array}$ \\
\hline 2.5. inhA-T15+ inhA-A8 & 0 & 0 & 0 & 0 & 1 & 2,6 & - \\
\hline 3. katG+inhA & 7 & 10,3 & 17 & 11,6 & 3 & 7,9 & $\begin{array}{l}1-2=0,6679 \\
1-3=0,7343 \\
2-3=0,4863\end{array}$ \\
\hline 3.1 ser315->Thr1+inhA-A8 & 2 & 2,9 & 2 & 1,4 & 1 & 2,6 & $\begin{array}{l}1-2=0,6508 \\
1-3=0,9285 \\
2-3=0,5008\end{array}$ \\
\hline
\end{tabular}


Окончание таблищы 3

\begin{tabular}{|c|c|c|c|c|c|c|c|}
\hline \multirow{2}{*}{$\begin{array}{l}\text { Мутации в генах, кодирующих лу } \\
\text { к изониазиду (INH) }\end{array}$} & \multicolumn{2}{|c|}{ Группа $1(n=68)$} & \multicolumn{2}{|c|}{ Группа 2 ( $n=147)$} & \multicolumn{2}{|c|}{ Группа $3(n=38)$} & \multirow{2}{*}{$p$} \\
\hline & абс. & $\%$ & абс. & $\%$ & абс. & $\%$ & \\
\hline 3.3 ser315->Thr1->Gly & 2 & 2,9 & 5 & 3,4 & 0 & 0 & $1-2=0,7177$ \\
\hline 4.katG+inhA+ahpC & 2 & 2,94 & 2 & 1,4 & 0 & 0 & $1-2=0,7177$ \\
\hline 5. $a h p C$ & 3 & 4,4 & 0 & 0 & 0 & 0 & - \\
\hline Всего & 38 & 56,0 & 76 & 51,8 & 11 & 28,9 & $\begin{array}{l}1-2=0,5852 \\
1-3=0,0087 \\
2-3=0,0122\end{array}$ \\
\hline
\end{tabular}

группы 1, в 76/147 (51,8\%) - группы 2, что было достоверно больше по сравнению с группой 3 $11 / 38(28,9 \%), p_{1-2}=0,5852, p_{1-3}=0,0087, p_{2-3}=0,0122$.

INH проникает в организм в виде пролекарства и только после процесса его активации и окисления ферментом каталазой-пероксидазой превращается в активное производное, способное ингибировать синтез миколовой кислоты МБТ. Мутации в гене $k a t G$ нарушают способность каталазы окислять INH, что приводит к формированию к нему ЛУ $[5,10,11]$. Мутации в гене katG являются основными и, как правило, ассоциируются с высоким уровнем ЛУ [3]. В нашем исследовании число мутаций в гене $k a t G$ в группе 1 составило 21/68 (30,9\%), в группе 2 $48 / 147$ (32,7\%), что было достоверно больше по сравнению с группой $3-4 / 38(10,5 \%), p_{1-2}=0,7710$, $p_{1-3}=0,0224, p_{2-3}=0,0081$. Наибольшее число мутаций во всех трех группах в гене $k a t G$ наблюдалось в 315-м кодоне (табл. 3).

По данным литературы [4, 11, 15], мутация ser 315-> Thr встречается наиболее часто и является неблагоприятной, так как INH-устойчивые штаммы МБТ с этой мутацией сохраняют полную вирулентность, обусловливают высокий уровень ЛУ, а также обладают наибольшим потенциалом широкого распространения в качестве изолятов МЛУ [13]. Мономутация ser 315-> Thr встречалась в большинстве клинических изолятов и составила 16/68 (23,5\%) в группе 1, 32/147 (21,8\%) - в группе 2, 3/38 (7,9\%) в группе $3, p_{1-2}=0,7448, p_{1-3}=0,0434, p_{2-3}=0,0520$. Кроме того, данный вид мутаций наблюдался в комбинации с мутациями в генах $i n h A$ (двойные мутации): 7/68 (10,3\%) - в группе 1, 17/147 (11,6\%) - в группе 2 и $3 / 38(7,9 \%)$ - в группе 3 . Таким образом, в результате проведенных исследований установлено, что мутации в гене $k a t G$ и мутация ser 315-> Thr достоверно чаще встречались у лиц молодого и среднего возраста по сравнению с пациентами пожилого и старческого возраста (табл. 3).

В возникновении ЛУ к INH определенное значение имеют мутации на уровне гена $i n h A$ или его участка промотора [16], а также гена $\operatorname{ahp} C[5,12]$. В результате мутации в гене inhA наблюдается повышение содержания еноил-кислой фосфатредуктазы, а в гене $\operatorname{ahpC}$ - повышение фермента алкил-гидропероксидредуктазы, которые подавляют ингибирующее действие INH на микробную клетку, участвуя в процессе детоксикации его активного промежуточного продукта [3, 5]. Однако эти мутации наблюдаются значительно реже и, как правило, ассоциируются с низким уровнем устойчивости к INH [8]. В нашем исследовании не получено достоверных различий в частоте встречаемости этих мутаций как в виде мономутаций, так и их сочетаний с мутациями в гене $k a t G$ в трех группах наблюдения (табл. 3).

По данным литературы [14], ЛУ к RIF в 95\% случаев обусловлена мутациями в коротком фрагменте (81 пара нуклеотидов) гена $r p o B$, кодирующем 乃-субъединицу РНК-полимеразы. В нашем исследовании наибольшее число мутаций в гене $r p o B$ (включая МЛУ) обнаружено в группе 1 - 31/68 (45,6\%) и в группе 2 - 69/147 (46,9\%). Значительно меньше их выявлено в группе $3-10 / 38$ (26,3\%), $p_{1-2}=0,8914$, $p_{1-3}=0,0453, p_{2-3}=, 0207$ (табл. 4). Мутации были обнаружены в 531, 533, 511, 526, 515, 516, 512, 513-м кодонах гена $r p o B$. По данным литературы [9], мутации в 513, 526, 531-м кодонах ассоциированы с высокой степенью ЛУ к RIF, минимально ингибирующая концентрация (МИК) > 50 мкг/мл, что справедливо и для 516-го кодона (МИК > 64 мкг/мл). В нашем исследовании мутации в 531-м кодоне встречались значительно чаще других и были зарегистрированы во всех трех группах, но несколько в большем проценте случаев в группах 1 и 2 (21/68 (31\%) и 51/147 (35\%) соответственно) против группы $3-8 / 38(21,1 \%)$, однако различия не достигали достоверных величин (табл. 4). Наиболее часто встречающейся мутацией была Ser531->Leu, которая также в большем проценте случаев регистрировалась в группах 1 и 2 - 12/68 (17,7\%) и $37 / 147(25,2 \%)$ соответственно по сравнению с группой 3 - 5/38 (13,2\%) (табл. 5). Данный вид мутации имеет большое значение, так как не только обусловливает ЛУ к RIF высокого уровня [5], но и способствует повышенному риску возникновения ЛУ к другим препаратам первого ряда.

Мутации в 513-м и 526-м кодонах зарегистрированы в единичных случаях только у пациентов групп 1 и 2. Мутация Leu533->Pro ассоциируется с МИК > 32 мкг/мл [3], в нашем исследовании также встречалась в небольшом проценте случаев и только у пациентов групп 1 и 2 (табл. 5). Полученные данные позволяют предположить, что у пациентов группы 3 преобладает эндогенная реактивация туберкулезного процесса, на что косвенно указывает 
Таблица 4. Частота встречаемости мутаций в гене $r p o B$, кодирующих лекарственную устойчивость к рифампицину, включая МЛУ, у пациентов разных возрастных групп

Table 4. Frequency of mutations in rpoB genecoding resistance to rifampicin including MDR in the patients fromm different age groups

\begin{tabular}{|c|c|c|c|c|c|c|c|}
\hline \multirow{2}{*}{ Кодоны гена $r р о B$} & \multicolumn{2}{|c|}{ Группа $1(n=68)$} & \multicolumn{2}{|c|}{ Группа $2(n=147)$} & \multicolumn{2}{|c|}{ Группа 3 ( $n=38)$} & \multirow{2}{*}{$p$} \\
\hline & абс. & $\%$ & абс. & $\%$ & абс. & $\%$ & \\
\hline 531 & 21 & 30,9 & 51 & 34,7 & 8 & 21,1 & $\begin{array}{l}1-2=0,5646 \\
1-3=0,2709 \\
2-3=0,1012\end{array}$ \\
\hline 533 & 3 & 4,4 & 3 & 2,1 & 0 & 0 & $1-2=0,2279$ \\
\hline 511 & 1 & 1,5 & 9 & 6,1 & 1 & 2,6 & $\begin{aligned} 1-2 & =0,2005 \\
1-3 & =0,6912 \\
2-3 & =0,4661\end{aligned}$ \\
\hline 526 & 1 & 1,5 & 4 & 2,7 & 0 & 0 & $1-2=0,6735$ \\
\hline 515 & 0 & - & 0 & - & 1 & 2,6 & - \\
\hline 516 & 2 & 3 & 0 & - & 0 & - & - \\
\hline 512 & 2 & 3 & 2 & 1,36 & 0 & - & $1-2=0,2831$ \\
\hline 513 & 1 & 1,5 & 0 & - & 0 & - & \\
\hline Всего & 31 & 45,6 & 69 & 46,9 & 10 & 26,3 & $\begin{array}{l}1-2=0,8914 \\
1-3=0,0453 \\
2-3=0,0207\end{array}$ \\
\hline
\end{tabular}

Таблица 5. Спектр наиболее часто встречающихся мутаций в гене $r p o B$, кодирующих лекарственную устойчивость к рифампицину, у пациентов разных возрастных групп

Table 5. Ranges of the most frequent mutation in $r p o B$ gene coding resistance to rifampicin in the patients from differenr age groups

\begin{tabular}{|c|c|c|c|c|c|c|c|}
\hline \multirow{2}{*}{ Кодоны гена гроB } & \multicolumn{2}{|c|}{ Группа $1(n=68)$} & \multicolumn{2}{|c|}{ Группа $2(n=147)$} & \multicolumn{2}{|c|}{ Группа $3(n=38)$} & \multirow{2}{*}{$p$} \\
\hline & абс. & $\%$ & абс. & $\%$ & абс. & $\%$ & \\
\hline Ser531->Leu & 12 & 17,7 & 37 & 25,2 & 5 & 13,2 & $\begin{array}{l}1-2=0,1995 \\
1-3=0,5044 \\
2-3=0,1162\end{array}$ \\
\hline Leu533->Pro & 3 & 4,4 & 3 & 2,1 & 0 & - & $1-2=0,5044$ \\
\hline Ser531->Gln & 5 & 7,4 & 5 & 3,4 & 1 & 2,6 & $\begin{array}{l}1-2=0,2279 \\
1-3=0,2665 \\
2-3=0,7740\end{array}$ \\
\hline Ser531->Trp & 3 & 4,4 & 9 & 6,1 & 2 & 5,3 & $\begin{array}{l}1-2=0,7687 \\
1-3=0,8345 \\
2-3=0,8143\end{array}$ \\
\hline Ser531->Cys & 1 & 1,5 & 0 & - & 0 & & - \\
\hline Leu511->Arg & 1 & 1,5 & 4 & 2,7 & 1 & 2,6 & $1-2=0,6735$ \\
\hline His526->Leu & 1 & 1,5 & 4 & 2,7 & 0 & - & $1-2=0,6735$ \\
\hline Met515->Ile & 0 & - & 0 & - & 1 & 2,6 & - \\
\hline Ser512->Arg & 1 & 1,5 & 1 & 0,7 & 0 & - & - \\
\hline Asp516->Val & 2 & 2,9 & 0 & - & 0 & - & - \\
\hline Ser512->Thr & 1 & 1,5 & 0 & - & 0 & - & - \\
\hline GIn513->Gly & 1 & 1,5 & 0 & - & 1 & 2,6 & - \\
\hline Всего & 31 & 45,6 & 69 & 46,9 & 10 & 26,3 & $\begin{array}{l}1-2=0,8914 \\
1-3=0,0453 \\
2-3=0,0207\end{array}$ \\
\hline
\end{tabular}

выявленная у пациентов данной категории более низкая степень ЛУ к INH и RIF, регистрируемая на уровне генетических мутаций.

\section{Выводы}

1. У лиц молодого и среднего возраста по сравнению с пожилыми пациентами достоверно чаще регистрируются мутации одновременно в генах $k a t G, \operatorname{inh} A, \operatorname{ahpC}$ и в гене $r p o B$, что является основой для развития у них МЛУ (32,4 и 36,1\% против $13,2 \%$ соответственно).

2. Мутации в гене kat $G$ являются основными во всех трех группах, но статистически значимо чаще встречаются у лиц молодого и среднего возраста по сравнению с пациентами пожило- 
го и старческого возраста (30,9 и $32,7 \%$ против $10,5 \%)$.

3. Распространенность мутации ser $315->$ Thr гена $k a t G$ также в большинстве случаев встречается в клинических изолятах, полученных от больных молодого и среднего возраста по сравнению с пожилыми (23,5 и $21,8 \%$ против 7,9\% соответственно).
4. У пациентов пожилого и старческого возраста реже по сравнению с пациентами молодого и среднего возраста регистрируются мутации в гене $r р о B$ (26,5\% в группе 3 против 45,5\% в группе 1 и 46,9\% в группе 2). Статистически значимых различий нет в спектре мутаций в гене $r p o B$, кодирующих ЛУ к $\mathrm{RIF}$, между обследуемыми группами пациентов.

Конфликт интересов. Авторы заявляют об отсутствии у них конфликта интересов.

Conflict of Interests. The authors state that they have no conflict of interests.

\section{ЛИТЕРАТУРА}

1. Васильева И. А., Белиловский Е. М., Борисов С. Е., Стерликов С. А. Туберкулез с множественной лекарственной устойчивостью возбудителя в странах мира и в Российской Федерации // Туб. и болезни легких. - 2017. T. 95, № 11. - C. 5-17.

2. Галкин В. Б., Стерликов С. А., Баласаянц Г. С., Яблонский П. К. Динамика распространенности туберкулеза с множественной лекарственной устойчивостью // Туб. и болезни легких. - 2017. - Т. 95, № 3. - С. 5-12.

3. Дымова М. А., Ширшова А. Н., Храпов Е. А., Кожамкулов У. А., Петренко Т. И., Чередниченко А. Г., Филипенко М. Л. Молекулярные основы воз никновения лекарственной устойчивости у Mycobacterium tuberculosis // Вестник НГУ. - 2012. - Т. 10, № 2. - С. 243-249.

4. Исакова Ж. Т. Частота встречаемости и типы мутации в генах $r p o B, k a t G$, inhA и $\operatorname{ah} p \mathrm{C}$, ассоциированных с устойчивостью к рифампицину и изониазиду у штаммов M. tuberculosis, циркулируюших в Кыргызской Республике // Moлекулярная генетика, микробиология и вирусология. - 2008. - № 4. - С. 36-38.

5. Степаншин Ю. Г., Степаншина В. Н., Шемякин И. Г. Молекулярные механизмы устойчивости Mycobacterium tuberculosis к лекарственным препаратам // Антибиотики и химиотерапия. - 1999. - № 4. - С. 39-43.

6. Global tuberculosis report 2018. Geneva: World Health Organization; 2018,WHO/CDS/TB/2018.20

7. Gygli S. M., Borrell S., Trauner A., Gagneux S. Antimicrobial resistance in Mycobacterium tuberculosis: mechanistic and evolutionary perspectives // FEMS Microbiol Rev. - 2017. - Vol. 1, № 41 (3). - P. 354-373.

8. Hazbon M. H., Brimacombe M., Bobadilla del Valle M., Cavatore M., Guerrero M. I., Varma-Basil M., Billman-Jacobe H., Lavender C., Fyfe I. García-García L. Population genetics study of isoniazid resistance mytations and evolution of multidrug-resistant Mycobacterium tuberculosis // Antimicrob. Agents Chemother. - 2006. - Vol. 50, № 8. - P. 2640-2649.

9. Ohno H., Koga H., Kohno S., Tashiro T., Hara K. Relationchip between Rifampin MICs for and RpoB Mutations of Mycobacterium tuberculosis strains isolated in Japan // Antimicrob. Agents Chemother. - 1996. - Vol. 40, № 4. - P. 1053-1056.

10. Pym A. S., Domeneech P., Honore N., Song J., Deretic V., Cole S. T. Regulation of catalase-perodase expression, isoniasid sensitivity and virulence by furA of Mycobacterium tuberculosis // Molecular Microbiology. - 2001. - Vol. 40, № 4. - P. 879-889.

11. Saint-Joanis B., Souchon H., Wilming M., Johnsson K., Alzari P. M., Cole S. T Use of side-directed mutaenesis to probe the structure, function and isoniasid activation of the catalase/peroxidase, $k a t G$, from Mycobacterium tuberculosis // Biochem J. - 1999. - Vol. 338. - P. 753-760.

12. Streevatsan S., Pan X., Zhang Y., Deretic V., Musser J. M. Analysis of the oxyR-ahpC region in isoniazid-resistant and susceptible Mycobacterium tuberculosis complex organisms recovered from diseased humans and animals in diverse localities // Antimicrob. Agents Chemother. - 1997. - Vol. 41, № 3. - P. 600-606.

13. Taniguchi $\mathrm{H}$. Molecular mechanisms of multidrug resistance in Mycobacterium tuberculosis // J. UOEH. - 2000. - Vol. 1, № 22 (3). - P. 269-282.

14. Telenti A., Imboden P., Marchesi F., Lowrie D., Cole S., Colston M. J., Matter L. Schopfer K., Bodmer T. Detection of rifampicin resistance mutations in Mycobacterium tuberculosis // Lancet. - 1993. - Vol. 341. - P. 647-650.

15. Wengenack N. L., Uhl J. R., Saint-Amand A. L., Tomlinson A. J., Benson L. M., Naylor S., Kline B. C., Cockerill F. R., Rusnak F. Recombinant Mycobacterium tuberculosis Kat $G(\mathrm{~S} 315 \mathrm{~T})$ is a competent catalase-peroxidase with reduced activity toward Isoniazid // J. Infect. Dis. - 1997. - Vol. 176, № 3. - P. 722-727.

\section{REFERENCES}

1. Vasilyeva I.A., Belilovsky E.M., Borisov S.E., Sterlikov S.A. Multiple drug resistant tuberculosis in the world and Russian Federation. Tuberculosis and Lung Diseases, 2017, vol. 95, no. 11, pp. 5-17. (In Russ.)

2. Galkin V.B., Sterlikov S.A., Balasayants G.S., Yablonskiy P.K. Changes in the prevalence of multiple drug resistant tuberculosis Tuberculosis and Lung Diseases, 2017, vol. 95, no. 3, pp. 5-12. (In Russ.)

3. Dymova M.A., Shirshova A.N., Khrapov E.A., Kozhamkulov U.A., Petrenko T.I., Cherednichenko A.G., Filipenko M.L. Basic molecular mechanisms of drug resistance development in Mycobacterium tuberculosis. Vestnik NGU, 2012, vol. 10, no. 2, pp. 243-249. (In Russ.)

4. Isakova Zh.T. Frequency and types of mutations in $r p o B, k a t G$, inh $A$ and $a h p C$ genes associated with rifampicin and isoniazid resistance in M. tuberculosis, circulating in Kyrgyzstan Republic. Molekulyarnaya Genetika, Mikrobiologiya i Virusologiya, 2008, no. 4, pp. 36-38. (In Russ.)

5. Stepanshin Yu.G., Stepanshina V.N., Shemyakin I.G. Molecular mechanisms of drug resistance in Mycobacterium tuberculosis. Antibiotiki i Khimioterapiya, 1999, no. 4, pp. 39-43. (In Russ.)

6. Global tuberculosis report 2018. Geneva, World Health Organization, 2018,WHO/CDS/TB/2018.20.

7. Gygli S.M., Borrell S., Trauner A., Gagneux S. Antimicrobial resistance in Mycobacterium tuberculosis: mechanistic and evolutionary perspectives. FEMS Microbiol Rev., 2017, vol. 1, no. 41/3, pp. 354-373.

8. Hazbon M.H., Brimacombe M., Bobadilla del Valle M., Cavatore M., Guerrero M.I., Varma-Basil M., Billman-Jacobe H., Lavender C., Fyfe J., García-García L. Population genetics study of isoniazid resistance mytations and evolution of multidrug-resistant Mycobacterium tuberculosis. Antimicrob. Agents Chemother., 2006, vol. 50, no. 8, pp. 2640-2649.

9. Ohno H., Koga H., Kohno S., Tashiro T., Hara K. Relationchip between Rifampin MICs for and RpoB Mutations of Mycobacterium tuberculosis strains isolated in Japan. Antimicrob. Agents Chemother., 1996, vol. 40, no. 4, pp. 1053-1056.

10. Pym A.S., Domeneech P., Honore N., Song J., Deretic V., Cole S.T. Regulation of catalase-perodase expression, isoniasid sensitivity and virulence by furA of Mycobacterium tuberculosis. Molecular Microbiology, 2001, vol. 40, no. 4, pp. 879-889.

11. Saint-Joanis B., Souchon H., Wilming M., Johnsson K., Alzari P.M., Cole S.T. Use of side-directed mutaenesis to probe the structure, function and isoniasid activation of the catalase/peroxidase, $k a t G$, from Mycobacterium tuberculosis. Biochem J., 1999, vol. 338, pp. 753-760.

12. Streevatsan S., Pan X., Zhang Y., Deretic V., Musser J.M. Analysis of the oxyR-ahpC region in isoniazid-resistant and susceptible Mycobacterium tuberculosis complex organisms recovered from diseased humans and animals in diverse localities. Antimicrob. Agents Chemother., 1997, vol. 41, no. 3, pp. 600-606.

13. Taniguchi $\mathrm{H}$. Molecular mechanisms of multidrug resistance in Mycobacterium tuberculosis. J. UOEH, 2000, vol. 1, no. 22 (3), pp. 269-282.

14. Telenti A., Imboden P., Marchesi F., Lowrie D., Cole S., Colston M.J., Matter L., Schopfer K., Bodmer T. Detection of rifampicin resistance mutations in Mycobacterium tuberculosis. Lancet, 1993, vol. 341, pp. 647-650.

15. Wengenack N.L., Uhl J.R., Saint-Amand A.L., Tomlinson A.J., Benson L.M., Naylor S., Kline B.C., Cockerill F.R., Rusnak F. Recombinant Mycobacterium tuberculosis Kat $G(\mathrm{~S} 315 \mathrm{~T})$ is a competent catalase-peroxidase with reduced activity toward Isoniazid. J. Infect. Dis., 1997, vol. 176, no. 3, pp. 722-727. 
16. Wilson T. M., de Lisle G. W., Collins D. M. Effect of inh $A$ and $k a t G$ on isoniasid resistance and virulence of Mycobacterium bovis // Molecular Microbiology. 1995. - Vol. 15, № 6. - P. 1009-1015.

\section{ДЛЯ КОРРЕСПОНДЕНЦИИ:}

ФГБОУ ВО «Саратовский ГМУ им. В. И. Разумовского» МЗ РФ,

410012, г. Саратов, ул. Б. Казачья, Ә. 112.

E-mail:meduniv@sgmu.ru

\section{Салина Татьяна Юрьевна}

доктор медицинских наук, доцент, профессор кафедры фтизиатрии.

Тел.: 8 (8452) 51-40-65.

E-mail: SalinaTU@rambler.ru

\section{Морозова Татьяна Ивановна}

доктор медицинких наук, профессор,

заведующая кафедрой фтизиатрии.

Тел./факс: 8 (8452) 26-16-90.

E-mail:dispans@san.ru
16. Wilson T.M., de Lisle G.W. Collins D.M. Effect of inh $A$ and $k a t G$ on isoniasid resistance and virulence of Mycobacterium bovis. Molecular Microbiology, 1995, vol. 15 , no. 6 , pp. 1009-1015.

\section{FOR CORRESPONDENCE:}

Saratov State Medical University named after V. I. Razumovsky, 112, B. Kazachya St.,

Saratov, 410012

Email:meduniv@sgmu.ru

\section{Tatiana Yu. Salina}

Doctor of Medical Sciences, Associate Professor,

Professor of Phthisiology Department.

Phone: + 7 (8452) 51-40-65.

Email:SalinaTU@rambler.ru

\section{Tatiana I. Morozova}

Doctor of Medical Sciences, Professor,

Head of Phthisiology Department.

Phone/Fax: + 7 (8452) 26-16-90.

Email:dispans@san.ru

Submitted as of 25.11.2018 